\title{
CONFRONTING SUBTLE SEXISM IN AN INDONESIAN EFL TEXTBOOK
}

\author{
Ana Humardhiana \\ IAIN Syekh Nurjati Cirebon \\ anahumardhiana@gmail.com \\ Yayah Nur Hidayah \\ IAIN Syekh Nurjati Cirebon \\ yayahnurh@yahoo.com.au
}

\begin{abstract}
Sexism, an ideology of which practices partake in demeaning or ignoring females or males or stereotyping either sex, can be dimmed to some extent. This type of sexism is called subtle sexism. In Indonesia, subtle sexism can be found in EFL textbooks. It is 'softly' hidden on the pages and readers - students in this case - are not aware that they are being indoctrinated. This study examined an Indonesian EFL textbook entitled Bahasa Inggris Kelas XII for the twelfth graders in Indonesia, which was published by the Ministry of Education and Culture. By implementing content analysis, a method typically used to examine the content of a textbook, this research has two objectives, i.e. (1) to find out whether the book promotes subtle sexism, and (2) how teachers, as the last filters, can confront subtle sexism in the book and other EFL textbooks in general. The results show that even though the textbook does not reflect any signs of blatant and covert sexism, it still promotes subtle sexism that the writers might not aware of. Also, this study tries to propose some suggestions for teachers to confront subtle sexism in EFL textbooks, such as using a gender bias checklist, making changes or creating new original materials, fostering a critical class discussion by using the sexist textbooks, and teaching gender-fair language.
\end{abstract}

Keywords: sexism, subtle sexism, EFL textbooks, gender-fair language, gender equality

\section{BACKGROUND}

As a tool to communicate thoughts and ideas, language is very powerful to embed certain ideologies. The process of implanting these ideologies can be so subtle that the decoding people would not know they are actually being indoctrinated. One of the ideologies that has been subtly embedded in our society is sexism. Sexism is an ideology of which practices partake in demeaning or ignoring females or males or stereotyping either sex; it is most of the time not a question of intention but of effect (LSA bulletin in Ansary \& Babaii, 2003). Rarely does sexism appear directly, but the effect is manifested in real gender issues, from certain gender exclusion and/or discrimination to gender inferiority. At worst, 
extreme sexism can feed sexual harassment, rape, and other forms of sexual violence (Mishra \& Khatun, 2017).

In Indonesia, sexism has strengthened its roots deep in every setting of life, from work to home. Sexism at the workplace may occur in the forms of excluding women who have children from career opportunities, ignoring or silencing women in meetings, favoring a man rather than a woman for a managerial position by presuming her lack of authority, and many others. Whereas sexism at home often appears in the form of forcing a daughter to get married before 25 or keeping asking her when to get married, making women serve for the guests and do the house chores, to name but a few. In the educational setting itself, sexist attitudes can be as overt as sexual harassment and gender stereotypes. They can also be as subtle as illustrations in textbooks portraying male police officers and cleaning moms or reading passages in where females are given less portion of occurrence, which are usually found in EFL textbooks. The Global Education Monitoring Report by UNESCO (2020) shows that "girls and women only made up $44 \%$ of references in secondary school English-language textbooks in Malaysia and Indonesia, 37\% in Bangladesh and $24 \%$ in the province of Punjab in Pakistan". The annual report points out that females are still under-represented in school textbooks in Indonesia and worldwide.

In a foreign language learning class, textbooks are a crucial component. They may perform as the main language input received by the students or as the media for them to have language practice (Tomlinson in Herlinda, 2014). As the main language input, textbooks can transfer cultural values and ideologies through the targeted language. Sexism is mostly found in them, be it in the reading passages, listening passages, or grammar and vocabulary exercises. The phrases "boys and girls", "brothers and sisters", and "my mom cooks and my dad works" sound so acceptable that the phrases "girls and boys", "sisters and brothers", and "my mom works and my dad cooks" sound awry. Society has constructed which gender should be put in the spotlight and which gender should take care of the kitchen at the back. This makes the utterance "My mom meets her clients at the office and my dad cooks lunch for us." get a rising eyebrow and skeptical questions. The speaker would instantly get questions like "So, your mom is the bread-winner? Why isn't your dad instead?", "So, your dad can cook? What about your mom?", or any other tactless responses. Those kinds of responses discredit and isolate one gender from another, resulting in the superiority-inferiority dichotomy.

That injust environment should not be in schools, places for children to get proper education and cultivate their social awareness. If this "hidden curriculum" (Stromquist et al. in Blumberg, 2015) continues, girls may further be constrained from realizing what they are capable of; and when they cannot reach their full potential, their families, communities, and nations cannot either (Bertini, 2011; Sadker, Sadker and Zittleman, 2009). Thus, teachers, as the last filters of the material input, must put efforts to provide healthy microenvironment which is free from all biases in order that female or male students can reach their full potential.

This research aims to raise awareness of sexism and help teachers of English confront subtle sexism in an Indonesian EFL textbook called Bahasa Inggris Kelas XII by the Ministry of Education and Culture and other EFL textbooks in general. There are two formulated questions that would be answered in this study, namely: 
1. Does Bahasa Inggris Kelas XII promote subtle sexism?

2. How can teachers, as the last filters, confront subtle sexism in the textbook? It is hoped that this study could ease EFL teachers, and possibly lecturers, to foster gender equality in teaching-learning activities. This study will also invite people to widen the horizon of awareness on such issues, which ultimately effaces any type of sexism.

\section{Subtle Sexism}

Sexism is a term that defines 'individuals' attitudes, beliefs, and behaviors, and organizational, institutional, and cultural practices that either reflect negative assessments of individuals based upon their gender or support unequal status of women and men" (Swim and Hyers in Becker et al., 2014). It is the root for gender biases, stereotypes, and any other unequal attitudes towards women and men. Gender itself is defined as "a constitutive element of social relationships based on perceived difference between the sexes" (Joan Scott in Echevarria, Short, \& Powers, 2006). For that comprehension, gender incorporates four elements, namely "culturally available symbols (like Adam and Eve or witches), normative concepts (which are embodied in religious, educational, scientific, and political doctrines), forms of subjective and inter-subjective identity, and forms of social organization in families, labor markets, education, and politics" (Fahriany, Alek, \& Wekke, 2019).

Sexism is comprised of many different forms, including blatant, covert, and subtle sexism. Blatant (or sometimes overt) sexism means "unequal and harmful treatment of women that is readily apparent, visible, and observable, and can be easily documented" (Benokraitis \& Feagin in Swim and Cohen, 1997). It often comes obviously and unambiguously, which potentially raises misogyny or ingrained prejudice against women. Cases related to blatant sexism are still everywhere despite the fact that this kind of sexism might be the primordial term to date back. Slightly different from blatant sexism, covert sexism limits to "unequal and unfair treatment of women that is recognized but purposefully hidden from view" (Swim et al., 2004). Some examples identified as covert sexism are wage discrimination between men and women which is not spoken about, not being allowed to go out at night by parents for being a woman, and using sexist language which degrades a certain gender, such as 'bitch', 'whore', and 'slut'. Even though covert sexism is different from blatant sexism in a way that it is hidden, both are actually intended.

The other form of sexist beliefs that not many people are aware of is subtle sexism which represents "unequal and unfair treatment of women that is not recognized by many people because it is perceived to be normative, and therefore does not appear unusual" (Swim et al., 2004). Similar to covert sexism, subtle sexism is hidden. It appears to be unintentional and harmless. It, however, is not, and dangerous in the long run. Subtle sexism has a subliminal message which may have insidious impact on its victims (Swim et al. in Swim et al., 2004). People who enact subtly sexist practices are usually in favor of gender equality, supporting egalitarian beliefs. However, these people may not realize when they or other people are treating others inequitably based on their gender or they may not notice that such behaviors lead to unequal and harmful treatment of women. For instance, in a school setting, teachers who teach equality at school and impassionedly 
mention girls and boys can be leaders, they, without any thoughts, always choose a male student as the captain of the class, leaving female students with no chances to show their potentials. Subtle sexism is so deeply ingrained that such treatments are perceived to be normal and customary.

\section{Sexist EFL Textbooks}

Textbooks are fundamental in an EFL class. Teachers use them as the instructional materials. Camera (2016) states that textbooks are used as the core means of teaching in about 70 to 95 percent of classroom time. With the high percentage of textbook use, Hutchinson and Torres in Herlinda (2014) add "...no teaching-learning situation, it seems, is complete until it has its relevant textbook". Textbooks also perform as the main language input received by the students or as the media for them to have language practice (Tomlinson in Herlinda, 2014). They are considerably the cheapest (sometimes the most accessible) and the most functional means to transmit knowledge and values. Hence, they are indispensable and widely used across the globe, including in Indonesia.

However, the concern of making good textbooks is mostly placed on its efficacy, how the content can be effective for students to learn English, when textbooks should actually transfer not only knowledge but also values from the social realities depicted. Apple and Christian-Smith in Esen (2007) add that textbooks are "...one of the most important mediums where the social realities are created from a certain aspect, through the knowledge and values that were included and excluded". Esen (2007) elaborates that while textbooks verify the correctness of the knowledge and values presented, they also confute those knowledge and values which they exclude. Therefore, textbooks carry out their social control function by legitimizing the power relations established between classes, groups, and sexes throughout the history and the dominating status of one class, group, or sex, as well. Hence, when there are social gaps and unequal treatments in society, good textbooks must not portray them in texts or illustrations, explicitly and implicitly. And this is a great deal but a revolutionary job for EFL textbooks writers.

Today, some EFL textbook writers have already tried to better balance both females and males to appear in the illustrations and texts, but subtle sexism can still be found in most pages in the books. Manos Antoninis, the Director of Global Education Monitoring (GEM) Report at UNESCO, points out that women and girls are too often represented in textbooks as 'nurturing drudges' in domestic roles worldwide and this is a 'hidden obstacle' to gender equality (Coughlan, 2016). Moreover in Indonesia specifically, it is perceived as normative for men to lead and be put in the spotlight and women to follow and take care of the kitchen at the back, thus making subtle sexism go unnoticable in textbooks, EFL textbooks especially. Sexist textbooks loaded with subtle sexism can be identified from these respective aspects taken from "Subliminal Sexism in Current ESL/EFL Textbooks" by Ansary and Babaii (2003), namely sex visibility, female/male topic presentation, sex-linked job possibilities, sex-based activity types, stereotyped sex roles, firstness, and masculine generic conception. Sex visibility is defined as the frequency of one sex representation against the other sex representation in both texts and illustrations. Female/male topic presentation deals with the number of times male-related or female-related are presented in dialogs and reading passages. Sex-linked job possibilities refer to certain occupational roles that are 'normal' for men and 
'normal' for women. Sex-based activity types talk about activity types that fit one sex and those that do not. Stereotyped sex roles discuss family roles which are stereotyped to a certain gender. Firstness deals with the masculine generic words that always come first before the feminine ones. Masculine generic conception refers to the conception which uses male-marked while referring to both sexes (Tao, 2008).

Besides that study entitled "Subliminal Sexism in Current ESL/EFL Textbooks" by Ansari and Babaii in 2003 which revealed that Right Path to English I \& II (Iranian ESL/EFL textbooks) were considered sexist textbooks, there are other previous studies investigating sexism in EFL textbooks. In China, a study entitled "Identifying and Combating Sexism in EFL Textbooks - with A Case Study into China" by Baiqiang Tao in 2008 explored methodologies of identifying and combating sexism in EFL textbooks. This study explained that we can identify sexism in EFL textbooks from these aspects: (sex) visibility, occupational and family roles, attributions (characteristics imposed upon females or males), and linguistic analysis (the investigation of how the language used based on its linguistic aspects, such as firstness, marked words for females while unmarked words for males, and masculine generic conception. Tao (2008) also pointed out some suggestions to combat sexism in EFL textbooks, i.e. (1) the legislature should enact laws to foster gender equality in a micro education environment, (2) the awareness of gender equality should be nurtured and valued from the government to education practitioners, and (3) the principle of gender equality should be taken into consideration in EFL curriculum planning and designing, EFL textbook designing, censoring, and selecting.

Quite a recent and similar study conducted in Indonesia was a study by Cynantia Rachmijati and Sri Supiah Cahyati in 2018 entitled "Gender Representation in Textbook Bahasa Inggris Grade X". This study analyzed the representation of gender on Bahasa Inggris Kelas $X$ published by the Ministry of Education and Culture in Indonesia. The findings showed that (1) male was presented and mentioned slightly better than female; (2) male was portrayed in a wider range of social settings than female; (3) there were not too many domestic roles and settings found in the book possibly due to the fact that the book was written to inline with Curriculum 2013, of which the main purpose is to develop social skills; and (4) findings related to the Text were $4.11 \%$ visual characters, $28.77 \%$ characters mentioned, $57.54 \%$ social activities, and $9.58 \%$ domestic activity, whereas findings related to Visual were $88.89 \%$ social activities and $11.11 \%$ domestic activities, meanwhile the Frequency of Occurrence for males was $51.89 \%$ and females was $48.11 \%$. The conclusion suggested that gender representation in the book was dominated by males.

\section{METHOD}

This research has two objectives, namely to find out whether Bahasa Inggris Kelas XII, an EFL textbook for the twelfth graders in Indonesia published by the Ministry of Education and Culture, promotes subtle sexism, and how teachers, as the last filters, can confront subtle sexism in the textbook. Thus, content analysis with a quantitative and qualitative approach was considered suitable. Qualitative research seeks to understand a phenomenon by focusing on the total picture rather than breaking it down into variables like quantitative research does. Ary, Jacobs, 
and Sorensen (2010) state that the goal of qualitative research is a holistic picture and depth of understanding rather than a numeric analysis of data. Furthermore, Creswell (2007) points out the reason for conducting qualitative research is that the researchers want to understand the contexts or settings in which participants in a study address a problem or issue. Since in this study 'the participant' was a textbook, content analysis helped with the findings.

"Content analysis is a research method that provides a systematic and objective means to make valid inferences from verbal, visual, or written data in order to describe and quantify specific phenomena" (Downe-Wambolt in Bengtsson, 2016). Byrd (2001) adds that content analysis is used to examine whether the content is interesting, offensive, fair, or discriminatory. In this research, content analysis was employed to investigate subtle sexism hidden in the texts and illustrations of Bahasa Inggris Kelas XII. Analysis of EFL/ESL books' content is a key contemporary issue in English language teaching and applied linguistics (Hall and Hewing, 2001), which unfortunately does not get as much spotlight as analysis of EFL/ESL books' efficacy. Hence, a content analysis of EFL textbooks in Indonesia has to be conducted as frequently as an analysis of the effectiveness of the books so that not only do the books teach the target language to the students, but also educate them and raise their awareness on certain social issues, in this case sexism in educational settings.

In conducting this research, there were several procedures for the data collection and analysis. First, the researcher selected the textbook. The textbook called Bahasa Inggris Kelas XII which was published by the Ministry of Education and Culture drew the researcher's attention because of its wide use and easy accessibility on the internet. Next, the book was examined and studied in depth based on two categories, i.e. texts and illustrations. After that, qualitative inquiry models by Ansary and Babaii (2003) and Tao (2008) were implemented. The inquiries were made into sex visibility, female/male-oriented topic presentation, sex-linked job possibilities, stereotyped sex roles and activities, attributions, and linguistic analysis which comprises of firstness and masculine generic conception. In addition, this research followed some procedures to establish trustworthiness outlined by Creswell (2007), namely prolonged engagement, triangulation of sources, theory/perspective triangulation, and member checking.

\section{FINDINGS AND DISCUSSION}

By implementing content analysis, this research investigated an EFL textbook entitled Bahasa Inggris Kelas XII for the twelfth graders in Indonesia which was published by the Ministry of Education and Culture. It has a blue cover with some pictures of famous places around the world. Through its 176 pages, this book implements Curriculum 2013 which emphasizes the importance of the balance of behavioral, knowledge, and skill competencies in English learning. This book is accessible on the internet in order to ease students and teachers. The book was first published in 2013 and the revised edition was published in 2018. The latter was then the one investigated.

The investigation and analysis performed in this research were in the matter of subtle sexism. They were conducted to find out whether Bahasa Inggris Kelas XII promotes subtle sexism and how teachers can confront subtle sexism in the textbook, and other EFL textbooks in general. The research findings and discussion 
are presented in two sections, namely A Book Promoting Subtle Sexism and Confronting Subtle Sexism.

\section{A Book Promoting Subtle Sexism}

This section addresses the results of quantitative and qualitative content analysis which would answer the first research question, "Does Bahasa Inggris Kelas XII promote subtle sexism?". The quantitative content analysis presents the analysis of the data based on the frequency of occurrence with reference to sex visibility in both texts and illustrations, as well as female or male-oriented topic presentation in dialogs and reading passages. The results are as follow.

Table 1. Frequency of Male and Female Occurence in Texts and Illustrations

\begin{tabular}{|l|c|c|}
\hline \multirow{2}{*}{ Female } & Illustrations & Texts \\
\cline { 2 - 3 } & 57 & 47 \\
\hline \multirow{2}{*}{ Male } & $50 \%$ & $49 \%$ \\
\cline { 2 - 3 } & 57 & 49 \\
\hline \multirow{2}{*}{ Total } & $50 \%$ & $51 \%$ \\
\cline { 2 - 3 } & 114 & 96 \\
\hline
\end{tabular}

The table shows that females and males appeared equally in the illustrations in the book. This is a good indicator that the book or in this case the writers are aware enough of sexism. They took the first step to put females on the spotlight by giving them the same portion as the male counterparts in the illustrations. Meanwhile in the texts, the occurrence of males is seen to slightly outnumber that of females with $2 \%$ higher portion. This approves that males are still dominant at a certain level.

An examination of female or male-oriented topic presentation in dialogs and reading passages was also conducted. The result is presented in the following table.

Table 2. Female/Male-Oriented Topic Presentation in Dialogs and Reading Passages

\begin{tabular}{|l|c|c|}
\hline \multirow{2}{*}{ Female } & Dialogs & Reading Passages \\
\cline { 2 - 3 } & 6 & 1 \\
\hline \multirow{2}{*}{ Male } & $46.2 \%$ & $5.5 \%$ \\
\cline { 2 - 3 } & 6 & 1 \\
\hline Neutral/ & 1 & $5.5 \%$ \\
\cline { 2 - 3 } Balanced & $7.6 \%$ & 16 \\
\hline Total & 13 & $89 \%$ \\
\cline { 2 - 3 } & $100 \%$ & 18 \\
\hline
\end{tabular}

Table 2 shows that most topic presentations are balanced or genderlessoriented in the reading passages, given 18 passages in total but only one passage that is female or male-oriented. Whereas, male-oriented topic presentation covers six dialogs, which is the same number as female-oriented one, leaving one dialog 
for neutral-oriented topic presentation. This suggests a positive gesture of improvement.

A qualitative content analysis was also conducted to support the numeric data. The qualitative inquiry was made into sex-linked job possibilities, stereotyped sex roles and activities, attributions, and linguistic analysis which comprises firstness and masculine generic conception. All of those categories were found in the book in some mentioned pages.

\section{Sex-linked Job Possibilities}

An inquiry into sex-linked job possibilities revealed that the manifestation of female/male occupational capacity restriction portrayed men delighted in a wide variety of jobs, doctor, police officer, soldier, employer, manager, singer, teacher, and cook, to name but a few. While women were still shown to be plotted in certain jobs, such as nurse, teacher, student, secretary, front officer, and employee. Those occupational roles could be seen on page $4,5,40,50,54$,

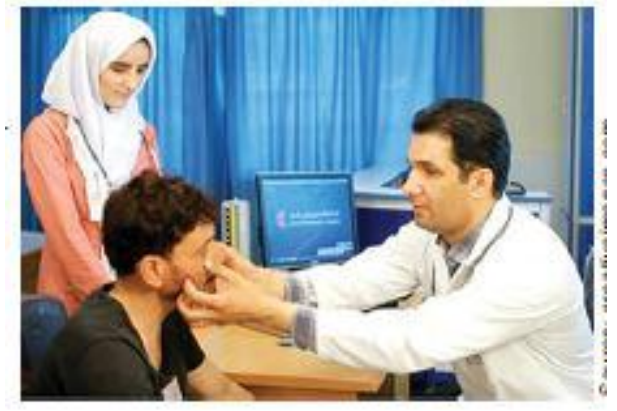

Picture 1. Sex-linked Job Possibilities for Females and Males on page 4 57, and 61. This finding confirms Ansary and Babaii (2003) that women are often portrayed to have restricted occupations. They are still confined to such office-related jobs, while men have already enjoyed a wider range of occupational roles from high-paying and respectable jobs to assisting and serving jobs.

\section{Stereotyped Sex Roles and Activities}

Stereotyped sex roles and activities became the next inquiry made to investigate sexism in the book. This investigation revealed that women were depicted to do indoor activities which are 'normally' appropriate for them, such as caring and assisting for the family, whilst men could do more roles, such as decisionmakers and outdoor active roles. One of the clear depictions was on page 6

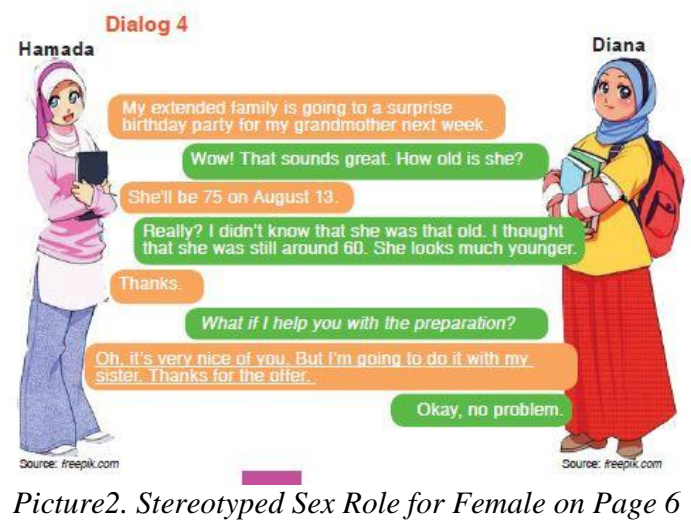
where there were two female students talking about a surprise birthday party of one of the students' grandmother. It shows that females are stereotyped to do the role of a caretaker for the family members. Conversely, on page 20, two males were portrayed talking about visiting touristic places, giving an active-outdoorsy stereotype to men. Other pages that contributed to stereotyped sex roles and activities of both genders were page 4, 8, 9, 69, 79, and 103. This finding agrees with Ansary and Babaii (2003) and Tao (2008) stating that males mostly take outdoor roles and activities, while females do more traditional ones. 


\section{Attributions}

This inquiry was made to examine what traits and characteristics attributed to males and females as seen in the book. Apparently, even though not many, Bahasa Inggris Kelas XII still showed some attributions to females and males as seen on page 52, 77, and 103. On page 52 number 7, Maya, a female student, was described as calm. While on page 77, Harold Pinter, a male British playwright, was said to be outspoken. The attributions given specifically to women and men may seem 'normal', but they construct how women and men should be and behave in society. This contributes to gender stereotypes, which supports the study of Tao (2008) stating that some feminine qualities might be considered as sexist attitudes against females, where women who possess firm and strong traits are considered to lack feminity; and men who embrace gentle and sensitive traits are considered to lack masculinity. They are assumed to be unable to fit in the personality they are supposed to possess.

\section{Linguistic Analysis}

The analysis on linguistic aspects was conducted regarding firstness and masculine generic conception. Firstness was seen on page 12,60, and 83 where the masculine word always came first in given two words paired for sex, such as his/her, $\mathrm{him} / \mathrm{her}$, and some others. Masculine generic conception itself was not found in the textbook, again indicating that the book has started to have a positive gesture towards gender equality. However, with the finding of firstness, subtle sexism is agreed to go unnoticeable in EFL textbooks. Firstness of masculine words reflects that women should not be put in the spotlight and are perceived to be less important than men. This confirms Ansary and Babaii (2003) and Tao (2008) that women are reinforced chiefly to take the second-place status.

\section{Confronting Subtle Sexism}

The data presented above shows that the writers of the book were aware of sexism and gender bias. Thus, they tried to give an equal portion to females and males in illustrations and texts. Nevertheless, subtle sexism, delivered by unconscious minds, still exists in the textbook, hiding in some pages, waiting to engrain a subliminal message to the book's readers. Teachers, as the last filters, can do something about it. This study is suggesting some advice to help teachers confront subtle sexism hidden in Bahasa Inggris Kelas XII and other EFL textbooks in general.

Prior to teaching English using EFL textbooks, there are two stages to consider in order to confront subtle sexism. The first stage deals with teachers' prepreparation. In this stage, teachers can start with a checklist to identify gender bias in the textbooks and curriculum for a broader scope. They can use the checklist guidelines by UNESCO for this problem. There are at least five guidelines to consider about: (1) are the materials used by the teacher or students free from gender stereotypes?; (2) do the materials show females and males an equal amount of times?; (3) do the materials show females and males with equal respect and potential (when talking about jobs, or future, for example)?; (4) does the curriculum reflect the needs and life experiences of both males and females?; and (5) does the 
curriculum promote peace and equality for males and females, regardless, of their race, class, disability, religion, sexual preference, or ethnic background? (Dierking, 2017). With these guidelines, not only can teachers provide 'healthy' materials for their students, but they can also improve their awareness on sexism, be it subtle or not, and become more skilled in identifying gender inequality in textbooks and other materials.

The second stage focuses on the class preparation where teachers can set up the materials. In this stage, teachers improve their textbooks or materials by making changes or creating new original materials (Dierking, 2017). There are also UNESCO guidelines that might help those efforts, such as (1) ensure that both genders are shown equally in the materials, (2) ensure that the themes, subjects, and pictures used in the materials relate to the life experiences of both genders, (3) ensure that both genders are not presented only in stereotypical ways, (4) ensure to use a balanced amount of textbooks or other materials written by female and male authors, and (4) include both genders as examples of experts or leaders (Dierking, 2017). In case that teachers have little time to create new materials, they can use the sexist textbooks for a class discussion so that students can boost their critical thinking to get sensitive with such issues. Also, teachers can teach gender-fair language (GFL) to the students. GFL is a reformed language to abolish structural asymmetries in order to reduce gender stereotyping and discrimination in the language (Fairclough and Maass et al. in Sczesny, Formanowicz, \& Moser, 2016). There are two fundamental strategies to make languages gender-fair, namely neutralization and feminization. Neutralization is seen as a strategy to replace gender-marked terms with gender-indefinite nouns, for instance, the English word 'policeman' is replaced by 'police officer'; meanwhile, feminization refers to an attempt of explicit inclusion of women (Sczesny, Formanowicz, \& Moser, 2016). This attempt is achieved in several ways, one of which is replacing masculine generics with feminine-masculine word pairs, e.g. 'he' is replaced by 'she or he'. This stage requires lots of efforts. Yet, with such efforts, teachers can help eliminate sexist attitudes among students. They can also create a stronger-healthier learning environment where all students get a chance to reach their full potentials.

However, confronting subtle sexism in EFL textbooks will be a neverending work for teachers if there is no support from the government. Thus, the principles of gender equality should be included in EFL curriculum planning and textbook designing. Female experts and sociolinguists appointed by the government would make sure that gender equality is reinforced in EFL textbooks.

\section{CONCLUSION}

To sum up, even though Bahasa Inggris Kelas XII published by the Ministry of Education and Culture in Indonesia does not reflect any signs of blatant and covert sexism, it still promotes subtle sexism that the writers might not aware of. The subtle sexism is hidden in some illustrations and texts reflecting sex-linked job possibilities for females and males, stereotyped sex roles and activities, constructed traits and characteristics attributed to males and females, and masculine words that always come first before the feminine words (firstness).

To tackle down the issue, teachers, as the last filters can confront subtle sexism by making a checklist to identify gender bias in the textbooks and curriculum for a broader scope in the pre-preparation stage. They can benefit from 
the UNESCO checklist guidelines. In the preparation stage, teachers can then improve their textbooks or materials by making changes or creating new original materials. If teachers have little time to create new materials, they can use the sexist textbooks for a class discussion to boost students' critical thinking to get more sensitive with such issues. In addition, teachers can teach gender-fair language to the students in order to reduce gender stereotyping and discrimination in language. However, these attempts will unlikely to succeed if the government does not take subtle sexism seriously into consideration in EFL curriculum planning and textbook designing.

\section{REFERENCES}

Ansary, H., \& Babaii, E. (2003). Subliminal Sexism in Current ESL / EFL Textbooks. The Asian EFL Journal, Volume 5.(1). Retrieved from http://asian-efl-journal.com/march03.sub1.pdf

Ary, D., Jacobs, L. C., \& Sorensen, C. (2010). Introduction to Research in Education (8th ed). California: Wadsworth.

Bengtsson, M. (2016). How to plan and perform a qualitative study using content analysis. NursingPlus Open. doi:10.1016/j.npls.2016.01.001

Bertini. (2011). Girls Grow: A Vital Force in Rural Economies. Chicago, IL: Chicago Council on Global Affairs.

Byrd, P. (2001). Textbooks: Evaluation for selection and analysis for implementation. In M. Celce-Murcia (Ed.), Teaching English as a second or foreign language. (3rd ed.) (pp. 415-424). Boston: Heinle \& Heinle.

Camera, L. (2016, March 8). How children around the world learn to be sexist. U.S. News. Retrieved from https://www.usnews.com/news/articles/2016-0308/sexism-in-textbooks-a-worldwide-problem

Coughlan, S. (2016, March 8). International women's day: sexism rife in textbooks, says UNESCO. BBC. Retrieved from https://www.bbc.com/news/education$\underline{35745327}$

Creswell, J. W. (2007). Qualitative Inquiry \& Research Design: Choosing Among Five Approaches, Second Edition. London: Sage Publications Inc.

Dierking, P. (2017, August 22). How to identify gender inequality in teaching materials. VOA Learning English. Retrieved from https://learningenglish.voanews.com/a/how-to-identify-gender-inequalityin-teaching-materials/3996027.html

Esen, Y. (2007). Sexism in School Textbooks Prepared under Education Reform in Turkey Yasemin Esen University of Ankara, Turkey. Retrieved from https://bit.ly/2YqcW50

Fahriany, F., Alek, A., \& Wekke, I. S. (2019). Gender Representation in English Textbooks for Islamic Junior High School Students. Kafa'ah: Journal of Gender Studies, 8(2), 149. doi:10.15548/jk.v8i2.221

Hall, D.R \& Hewing, A.(eds) (2001). Innovative in English Language Teaching. London Routledge.

Herlinda, R. (2014). The Use of Textbook in Teaching and Learning Process (A Study of Two EYL Teachers). Teflin, 61(1998), 359-362.

Mishra, S. \& Khatun, R. (2017). Women Education in Modern Perspective. New Delhi: Laxmi Book Publications. 
Sadker, D., Sadker, M., \& Zittleman, K. R. (2009). Still Failing at Fairness: How Gender Bias Cheats Girls and Boys and What We Can Do about It. New York: Charles Scribner.

Sczesny, S., Formanowicz, M., \& Moser, F. (2016). Can Gender-Fair Language Reduce Gender Stereotyping and Discrimination? Frontiers in Psychology. doi:10.3389/fpsyg.2016.00025

Swim, J. K., \& Cohen, L. L. (1997). Overt, Covert, And Subtle Sexism. Psychology of Women Quarterly, 21(1), 103-118. doi:10.1111/j.14716402.1997.tb00103.x

Swim, J. K., Mallett, R., \& Stangor, C. (2004). Understanding subtle sexism: Detection and use of sexist language. Sex Roles. doi:10.1023/B:SERS.0000037757.73192.06

Tao, B. (2008). Identifying and Combating Sexism in EFL Textbooks--With a Case Study into China. Online Submission.

UNESCO. (2020). Global education monitoring (GEM) report 2020. Retrieved from https://en.unesco.org/news/global-education-monitoring-gem-report$\underline{2020}$

Widiati, U., Rohmah, Z., \& Furaidah. (2018). Bahasa Inggris kelas XII. Jakarta: Kementerian Pendidikan dan Kebudayaan. 